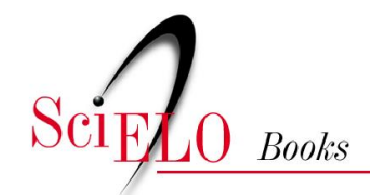

\title{
Cosmologia e ética no tempo de Giordano Bruno
}

\author{
Pietro Daniel Omodeo
}

OMODEO, P.D. Cosmologia e ética no tempo de Giordano Bruno. In: PINTO, F.M., and BENEVENUTO, F., comps. Filosofia, política e cosmologia: ensaios sobre o renascimento [online]. São Bernardo do Campo, SP: Editora UFABC, 2017, pp. 273-307. ISBN: 978-85-68576-93-9. https://doi.org/10.7476/9788568576939.0014.

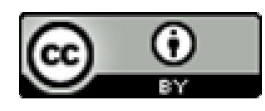

All the contents of this work, except where otherwise noted, is licensed under a Creative Commons Attribution 4.0 International license.

Todo o conteúdo deste trabalho, exceto quando houver ressalva, é publicado sob a licença Creative Commons Atribição $\underline{4.0}$.

Todo el contenido de esta obra, excepto donde se indique lo contrario, está bajo licencia de la licencia $\underline{\text { Creative }}$ Commons Reconocimento 4.0. 
Doutor em filosofia pela Universidade de Turim, na Itália, e mestre pela mesma instituição, em 2004. Tem experiência na área de Filosofia e História da Ciência, pesquisando principalmente sobre os seguintes temas: Copérnico, Giordano Bruno, Nicolau de Cusa, Cosmologia, ontologia e ética. Atualmente é pesquisador do Max Planck Institute for the History of Science, em Berlim, e autor do livro: Copernicus in the cultural debates of the Renaissance: reception, legacy, transformation (Brill), publicado em 2014. 


\section{COSMOLOGIA E ÉTICA NO TEMPO DE GIORDANO BRUNO ${ }^{1}$}

Pietro Daniel Omodeo ${ }^{2}$

No século XVI, a Europa viveu uma crise marcada pela cisão entre as confissões religiosas e pelos enrijecimentos doutrinários. Foi, ao mesmo tempo, um período de renovação científica e cultural. Sínteses filosóficas novas e precárias, que muitas vezes traziam consigo visões ecléticas da natureza, do cosmos e do homem - colocaram em discussão as autoridades consolidadas e as concepções cristalizadas sobre a piedade, a transcendência e o divino. $\mathrm{O}$ estudo da obra e da biografia de Giordano Bruno oferece ao historiador um acesso privilegiado à cultura filosófica e científica do Renascimento e aos seus trabalhos. Em sua obra, o poder desantropocentrizador intrínseco ao descentramento copernicano da Terra é levado

\footnotetext{
${ }^{1}$ A tradução deste artigo do italiano para o português foi gentilmente realizada pelo filósofo e Professor Associado na Universidade Federal do Rio Grande do Sul (UFRGS), Luiz Carlos Bombassaro.

${ }^{2}$ Pesquisador do Max Planck Institute for the History of Science, em Berlim.
} 
às últimas consequências por meio de uma visão infinitista do espaço e da pluralidade dos mundos - entendidos como sistemas solares análogos ao nosso. A reforma cosmológica bruniana era um convite para repensar o homem em sua relação com a natureza e com Deus ${ }^{3}$; mas a radicalidade desse apelo acabou por se deparar com a severa censura inquisitorial ${ }^{4}$.

Para comprender o entusiasmo e as preocupações que acompanharam primeiro a virada copernicana a depois aquela bruniana, considero oportuna uma descrição breve sobre o modo como as tendências humanísticas influenciaram as reflexões sobre a relação homem-mundo ${ }^{5}$. Farei referência especialmente ao modo como vem sendo tratado o tema do microcosmo e do macrocosmo em De disciplinis mathematicis, discurso de juventude de Tycho Brahe, representante máximo da astronomia matemática no tempo de Bruno. Em segundo lugar, procurarei ilustrar a crise da concepção humanística da harmonia antropológico-cosmológica que ganha destaque na visão antiantropocêntrica de Copérnico e Bruno. Essa reversão de perspectiva alimentou em Bruno expectativas milenarísticas, na convicção de que deveria se assistir em breve a uma renovação universal, ou seja, a um "Renascimento" filosófico-cultural e civil ${ }^{6}$. Para ilustrar essas expectativas brunianas,

\footnotetext{
${ }^{3} \mathrm{O}$ confronto e o desencontro de Bruno com as autoridades acadêmicas e eclesiásticas caracteriza a problemática complexa de seu modo de repensar infinitista em relação à cosmologia, antropologia, ética, política e religião. Para uma síntese elucidativa da concepção bruniana, em especial nos diálogos filosóficos italianos, ver: Granada (1999, p. IX-CXVIII); e Ordine (2004). Sobre as tensões ético-antropológicas e dos escritos vinculados à astronomia pós-copernicana e à cosmologia bruniana, tomo a liberdade de remeter ao meu texto (OMODEO, 2014, cap. 7 e 8 ).

${ }^{4}$ Referência imprescindível continua a ser Firpo (1993).

5 Trata-se de temas muito conhecidos dos estudiosos da cultura científica renascentista. Deles se ocupou Cassirer (1927). Ver também Garin (2007).

6 Sobre o 'milenarismo' de Bruno, especialmente no Spaccio de la bestia trionfante, ver Canone (2005, p. 53-65).
} 
vou me servir de algumas passagens extraídas dos diálogos filosóficos italianos publicados em 1584 e 1585. Especificamente, Bruno via na virada astronômica do De revolutionibus orbium coelestium copernicano o sintoma do início dos "novos tempos"; sua intenção era trazer maturidade à mudança em curso por meio do próprio projeto filosófico revolucionário. Por fim, mostrarei como o seu projeto teria de se deparar com o enrijecimento do dogma teológico na Itália pós-tridentina atendo-me ao processo inquisitorial, triste documento da intolerência religiosa na Europa moderna ${ }^{7}$. Pretendo rediscutir o caso Buno concentrando-me nos problemas cosmológicos e copernicanos que ganharam destaque e foram debatidos durante o processo.

\section{Astronomia e ética: topos clássico e humanístico}

A ideia de que a contemplação do firmamento e o estudo dos astros têm um valor ético intrínseco é talvez tão antiga quanto a própria disciplina. Os versículos da Bíblia exaltam os céus como epifania do Criador: "Caeli enarrant gloriam Dei, et opera manuum eius annuntiat firmamentum" ["Os céus contam a glória de Deus, e o firmamento proclama a obra de suas mãos."] (Salmos 18:2-3). Na cultura científica da Idade Média e do Renascimento difunde-se amplamente a convicção de que a astronomia não somente eleva a Deus, mas também ajuda a compreender o homem. Na base está a concepção antropocêntrica de acordo com a qual o homem seria o fim

7 Farei referência aos documentos do processo na edição francesa (BRUNO 2000). 
último da Criação. A exaltação da sua grandeza e a compaixão de suas misérias estão vinculadas às considerações sobre sua posição central, mas também ao ínfimo da sua morada. Para o humanismo quatrocentista, esses temas são elaborados em termos de uma correspondência entre homem e cosmos; a dignidade da figura humana é apresentada na posição ereta e no olhar voltado para o céu. E cabe a Pico della Mirandola, espírito voltado à concordância filosófica para além do particularismo das crenças e das escolas, um dos mais famosos elogios ao ser humano na época do florescimento da filologia e da retomada dos clássicos:

Assim, [Deus] tomou o homem como obra da natureza indefinida e, colocando-o no meio do mundo, falou-lhe deste modo: "Ó Adão, não te demos nem um lugar determinado, nem um aspecto que te seja próprio, nem tarefa alguma específica, a fim de que obtenhas e possuas aquele lugar, aquele aspecto, aquela tarefa que tu seguramente desejares, tudo segundo o teu parecer e a tua decisão. A natureza bem definida dos outros seres é refreada por leis por nós prescritas. Tu, pelo contrário, não constrangido por nenhuma limitação, determiná-la-ás para ti, segundo o teu arbítrio, a cujo poder te entreguei. Coloquei-te no meio do mundo para que daí possas olhar melhor tudo o que há no mundo. Não te fizemos celeste nem terreno, nem mortal nem imortal, a fim de que tu, árbitro e soberano artífice de ti mesmo, te plasmasses e te informasses, na forma que tivesses seguramente escolhido. Poderás degenerar até aos seres que são as bestas, poderás regenerar-te até às realidades superiores que são divinas, por decisão do teu ânimo ${ }^{8}$.

\footnotetext{
8 "Igitur [Deus] hominem accepit indiscretae opus imaginis, atque in mundi positum meditullio, sic est alloquutus: 'Nec certam sedem, nec propriam faciem, nec munus ullum peculiare tibi dedimus o Adam, ut quem sedem, quam faciem, quae
} 
A ideia de que existe uma correspondência entre o microcosmo homem e o macrocosmo celeste é uma herança clássica. No diálogo de Platão, intitulado Timeu, o pitagórico exalta a faculdade da visão enquanto sentido privilegiado capaz de elevar-se para além das coisas que passam. Os olhos abririam aos mortais um acesso privilegiado ao divino:

Nós diremos que a causa por que Deus inventou a visão e nô-la concedeu, é a seguinte: tendo contemplado no céu os movimentos da inteligência, que são da mesma natureza dos do nosso pensamento, porém perturbados; tendo estudado a fundo esses movimentos celestes, participado da retidão natural do raciocinar, imitando os movimentos divinos infalíveis, poderemos estabilizar os nossos, que não cessam de errar? .

As revoluções dos corpos celestes, suas recorrências períodicas e os ciclos de toda a natureza, além de mostrar

munera tute optaveris, ea pro voto, pro tua sententia, habeas et possideas. Definita caeteris [animalibus] natura intra praescriptas a nobis leges coercetur: Tu nullis angustiis coercitus, pro tuo arbitrio, in cuius manu te posui, tibi illam praefinies. Medium te mundi posui, ut circumspiceres inde commodius quicquid est in mundo. $\mathrm{Nec}$ te coelestem, neque terrenum, neque mortalem, neque immortalem fecimus, ut turpi ipsius quasi arbitrarius honorariusque plastes et fictor, in quam malueris tute formam effingas. Poteris in inferiora quae sunt bruta degenerare. Poteris in superiora quae sunt divina ex tui animi sententia regenerari.' O summam Dei patris liberalitetem, summam et admirandam hominis felicitatem. Cui datum id habere quod optat, id esse quod velit" (PICO DELA MIRANDOLA, De hominis dignitate, vol. 1, p. 314-315) [Aqui citado da edição portuguesa: PICO DELA MIRANDOLA, 1989, p. 49].

9 "Il dio ha trovato e ha donato a noi la vista, affinché, osservando nel cielo $i$ movimenti ciclici dell'intelligenza, ce ne servissimo per le circolazioni del pensiero che è in noi, le quali sono affini a quelli, sia pure come circolazioni non ordinate a circolazioni ordinate; e cosi, traendone insegnamento e partecipando alla rettitudine dei ragionamenti conformi a natura, imitando le circolazioni del dio che sono del tutto regolari, correggessimo le nostre circolazioni erranti" (PLATONE, Timeo 47 B-C. Traduzione a cura di Giovanni Reale in Platone, Timeo, 155). [Aqui citado da edição brasileira: Platão, Timeu. São Paulo: Hemus, 1981, p. 110]. 
a ordem e a beleza do cosmos, despertam em nós o sentido da harmonia e da medida, base da ética clássica da aurea mediocritas.

Isso não está distante da perspectiva estoica apresentada por Lucilio Balbo no De natura deorum ciceroniano. Aqui é o próprio Cícero que expõe o ponto de vista sofisticadamente antropocêntrico e teológico de acordo com o qual a função da visão é a de abrir ao homem a providência intrínseca do mundo do qual é espectador:

Em primeiro lugar, o deus elevou o homem da terra e o colocou em posição ereta, de pé, de modo que, contemplando o céu, pudesse ter alguma noção dos deuses. Os homens na verdade não habitam a Terra, mas em certo sentido são na Terra espectadores das realidades superiores e celestes, cuja contemplação não pertence a nenhuma outra espécie de seres viventes. [...] Os olhos, como observadores, ocupam a posição mais eleveda, da qual, gozando de uma perspectiva mais ampla, possam desenvolver as suas funções ${ }^{10}$.

Autores clássicos como Platão e Cícero faziam longas digressões sobre a perfeição do corpo humano com base na sugestiva ideia de uma correspondência entre anatomia humana e ordem natural, concepção que se tornaria herança da cultura científica medieval e renascentista, também graças às aplicações e implicações médicas e astrológicas.

\footnotetext{
10 "Quae primum eos [homines] humo excitos celsos et erectos constitit [providentia naturae], ut deorum cognitionem caelum intuentes capere possent. Sunt enim ex terra homines non ut incolae atque habitatores sed quasi spectatores superum rerum atque caelestium, quarum spectaculum ad nullum aliud genus animantium pertinet. [...] Nam oculi tamquam speculatores altissimum locum obtinent, ex quo plurima conspicientes fungantur suo munere" (CICERONE, De natura deorum, II, 56, p. 140ss. Tradução Luis Carlos Bombassaro (LCB)).
} 
Esses temas confluem para a cultura do humanismo alemão tardio, nos centros culturais da Reforma que foram muito influenciados pelas pregações de Philipp Melanchton e pela fusão eclética do credo luterano, do humanismo erasmiano e do naturalismo aristotélico ${ }^{11}$. Sirva de exemplo o discurso público De disciplinis mathematicis proferido em 1574 na Universidade de Rostock pelo jovem de dezoito anos Tycho Brahe, aristocrata dinamarquês de alta estirpe. O discurso, na verdade um elogio da astronomia e uma defesa da astrologia, é uma síntese de cultura humanística e melanchtoniana. Começa com uma divisão canônica das matemáticas em várias subdisciplinas, partindo da geometria e da aritmética ${ }^{12}$. Invariavelmente, aparece uma referência à antiga escola dos pitagóricos, aqueles que - de acordo com Brahe - mais do que ninguém revelaram o mistério da criação divina inscrita na ordem da natureza ${ }^{13}$.

Para um matemático marcado pela cultura do tempo, a piedade da astronomia reverbera nos citadíssimos versículos do Livro da sabedoria "Omnia in mensura et numero et pondere disposuisti" ["Tudo dispuseste com medida, número e peso"] (Liber sapientiae, 11:21). Rainha entre as matemáticas encontra-se, para Brahe, a astronomia, ciência destinada ao mais

\footnotetext{
${ }^{11}$ Referência standard sobre a questão da concepção melanchtoniana da astronomia, em particular da astrologia como ciência da Providência Divina, encontra-se em Kusukawa (1995).

12 Trato do gênero laudatio mathematicae em "Utilitas astronomiae". In the (RERANISSANCE, 2015).

13 A paixão pelo pitagorismo como filosofia apta a suportar uma abordagem matemática da natureza pode ser colocada no contexto de dois debates culturais importantes. O primeiro, concernente a certitudo mathematicarum foi estudado por De Pace (1993). O segundo é a astronomia copernicana, como bem mostrou a seu tempo Bilisnki (1977) e Omodeo (2014, seção 4, 4, p. 167-170. “The Invention of Pythagorean Cosmology".
} 
importante trabalho do Arquiteto supremo. A parte teórica revelaria o projeto matemático; a astrológica, o fim providencial. Brahe adere a tal perspectiva nitidamente melanchtoniana a ponto de considerar ímpios os críticos da astrologia: "É evidente que aqueles que afirmam que os astros não têm influência alguma sobre a nossa realidade terrestre negam a ordem e a providência de Deus"14. Na continuidade do discurso, aparecerá que os principais detratores da divinização são os filósofos da escola de Pico e os teólogos calvinistas ${ }^{15}$.

Brahe não deixa de considerar as correspondências astrológicas entre corpos celestes, caracteres humanos e anatomia. Os dois órgãos mais importantes, coração e cérebro, correspondem respectivamente aos maiores lumes, Sol e Lua. O fígado, fábrica do sangue, corresponderá a Júpiter, astro sanguíneo e vital; os rins, a Vênus, pela sua ligação com os órgãos genitais, e assim por diante.

Dada a estreita analogia entre os sete planetas e os sete principais órgãos do corpo humano - conclui Brahe - e dado que tudo está em tal consonância [para demonstrar] que o homem é quase perfeitamente conforme a ideia do mundo superior. Por isso, os filósofos tem razão em chamá-lo 'microcosmo'. Quem, pois, em plena posse de suas faculdades mentais, poderá negar que os corpos celestes têm influência sobre aqueles humanos, aos quais estão ligados pela forte semelhança em suas funções? ${ }^{16}$

\footnotetext{
14 "Apparet itaque, quam inique ordinationi et providentiae divinae contradicant, qui astrorum nullam esse asserunt in haec inferiora influentiam" (BRAHE. De disciplinis mathematicis, 1972, p. 143-174; p. 155).

15 A importância de Pico no debate astronômico do século XVI foi destacada, talvez de modo exagerado, por Westman (2011).

16 "Cum itaque tanta sit analogia inter septem Planetas et inter septem principalia membra in hominis corpore adeoque sibi omnia consentiant, ut quasi ad ideam
} 
Note-se que, não obstante a explícita tomada de distância em relação ao Pico das Disputationes in astrologiam, Brahe assume completamente a temática antropocêntrica do De hominis dignitate. Em suas mãos, isso torna-se uma alavanca a ser utilizada para minar a doutrina copernicana do movimento terrestre. Na verdade, a admiração que Brahe tem para como o rigor matemático do pai do heliocentrismo moderno é afetada pelas considerações acerca do absurdo físico das suas hipóteses. No discurso de 1574, ele não trata em detalhes as dificuldades da teoria copernicana ligadas à física e à cosmologia geocêntrica de matriz aristotélica, como fará nos escritos posteriores e particularmente na correspondência científica com o matemático heliocêntrico Christopher Rothmann, publicada em $1596^{17}$. O jovem Brahe salienta de modo especial a importância ética e providencial em colocar o microcosmo homem no centro da criação:

De acordo com a compreensão verdadeira e adequada de Deus, revelada por suas próprias palavras, considero que nada seja mais próprio à natureza humana $\mathrm{e}$ mais consoante ao fim pelo qual o homem foi criado e colocado na Terra, no centro do mundo, que contemplar, desde este lugar central, o que resplende na arquitetura do mundo (sobretudo no reino celeste onde refulgem tantas estrelas perpétuas), de modo que [o homem] passe suavemente a vida em prazeirosa e engenhosa contemplação. Assim, com justa veneração e louvor, ele celebrará Deus por conhecer suas sapientíssimas e muitas obras"18.

superioris mundi formatus esse homo, ideoque non immerito a philosophis Microcosmos appelletur: quis unquam sanae mentis negare poterit, coelestia corpora in humana, quibus tanta officiorum similitudine devincta sint, influere?" (BRAHE, 1972, p. 157-158).

17 Remeto à discussão apresentada em Omodeo (2014, p. 225-230).

18 "Post Dei veram et competentem cognitionem, nobis in verbo a se dato revelatam, nihil hominis naturae magis proprium, et finis propter quem homo in Terra, mundi 
Brahe declara que o prazer intelectual da contemplação dos céus nos eleva da efemeridade do nosso mundo, das vicissitudes "ridículas" ligadas à existência (a terrenis his, ridiculis et caducis rebus, ad coelestes... afficit et recreat). $\mathrm{O}$ amor e a investigação dos céus prepara o homem para a imortalidade destacando-o daquilo que é passageiro e dirigindo-o para o que há de mais puro e constante (BRAHE, 1972, 151).

Surpreende a candura quase ascética do jovem Brahe quando se leva em conta sua biografia intelectual e quando se considera que não houve, no século XVI, outro astrônomo tão propenso quanto ele às paixões, à ambição, à ira e à suspeita. Seu amor aos astros transforma-se numa atitude predatória diante dos agricultores das suas terras por causa da constante necessidade de recursos para investir no magnífico castelo e observatório de Uraniborg, com seus instrumentos de observação, o laboratório alquímico e a sua corte de matemáticos, literatos e cortesãos. A isso se acresce seu constante menosprezo aos méritos dos colaboradores, vistos como meros instrumentos do próprio trabalho, e as discussões ferozes com os outros matemáticos e astrônomos tachados de plágio por terem conseguido chegar, independente dele, a conclusões similares às suas ${ }^{19}$. O distanciamento do astrônomo das coisas terrenas não é, propriamente, a marca da atividade científica de Brahe ${ }^{20}$.

centro, conditus et collocatus sit, magis consentaneum esse judico, quam ut inde tanquam e loco medio, ea, quae in tota mundi fabrica, imprimis vero in coelesti illa et fulgentissima tot perpetuarum stellarum regia elucent, prospectans, jucunda hac et ingeniosa contemplatione aetatem suam suaviter transigat, Deumque opificem in his suis sapientissimis et variis operibus agnoscens, merita eum veneratione ac laude celebret" (BRAHE, 1972, p. 152).

19 Dentre os numerosos estudos sobre as controvérias geo-heliocêntricas de Brahe, ver especialmente Rosen (1986); Granada (1996); Jardine; Segonds (2008).

${ }^{20}$ Para um retrato provocativo de Brahe como senhor feudal que estende a lógica do poder senhorial à gestão da pesquisa científica, ver Conner (2005, 
É possível encontrar ainda outros exemplos de profunda ambivalência entre as declarações de intenções ascéticas e a ferocidade no debate com os contendores. Dentre eles podese recordar o caso do filósofo platônico Plotino, que foi muito importante na filosofia renascentista de Marsílio Ficino a Giordano Bruno. Pelos testemunhos de seu aluno e biógrafo Porfírio, Plotino era tão dedicado à transcendência a ponto de recusar-se a ser retratado, desejando com isso separarse da própria aparência terrena e do corpo mortal. Como se lê na abertura da Vida de Plotino, "o filósofo [...] parecia envergonhar-se de estar num corpo. Devido a esse estado de ânimo, não queria contar nada sobre o seus nascimento, nem sobre seus pais, nem sobre sua pátria" (PORFIRIO, 2002, p. 2-66). Mas esse distanciamento hierático diminuia rapidamente quando se tratava da riqueza. Numa outra passagem da mesma biografia, sabe-se que:

Plotino possuia uma capacidade extraordinária para interpretar os caracteres, tanto que, quando certa vez foi roubado um colar precioso [...] foram conduzidos diante dele todos os escravos, que ele após observálos, indicando um deles, exclamou: 'Este é o ladrão'. Após ter sido açoitado e após ter num primeiro momento negado insistentemente, ao final este confessou e restituiu aquilo que havia roubado (PORFIRIO, 2002, p. 25).

A maior virtude de Plotino não consistia evidentemente em sua prática como os escravos, mas na teoria. Dizse que, em seu leito de morte, ele convidava os seus alunos a

p. 321-325). Para um estudo detalhado das atividades realizadas no observatório astronômico de Brahe na ilha dinamarquesa de Hven e sobre as pessoas envolvidas no centro, ver Christianson (2000). 
contemplar o universo para se unir a Deus: "Procurai reconduzir o divino que está em vós para o divino que está no universo". Essa é a ideia central para a especulação cosmológica de Bruno, para quem a consciência íntima da infinitude divina é mediada pela contemplação do universo infinito e dos infinitos mundos, estrelas inumeráveis circundadas, como tantos sóis, por terras inumeráveis. Se Brahe podia se comprazer em exaltar a valência ética da astronomia à qual havia dedicado a própria vida desde uma posição privilegiada de um aristocrata poderoso e abastado; bem diversas são as condições nas quais escreveu e ensinou Bruno em sua aventurosa preregrinação europeia e em seu final trágico nas prisões da Inquisição. Como se depreende de uma delação do companheiro de cárcere em Veneza, Francesco Graziano: "Certa noite levou à janela Francesco Napolitano e lhe mostrou uma estrela, dizendo que ela era um mundo e que todas as estrelas eram mundos" (BRUNO, Le procès, doc. 51, p. 301).

Para o prisioneiro obrigado a observar as estrelas por uma janelinha da cela, a valência ética e anagógica da contemplação do universo, que liberta o espírito e o reconcilia com o infinito, é reforçada pelo caráter trágico das circunstâncias.

\section{Bruno e a reforma universal da ciência e dos costumes}

Giovanni Mocenigo, o anfitrião traidor que fez prender e entregou Bruno ao tribunal do Santo Ofício em Veneza, aduziu entre outras acusações

[...] que o havia ouvido dizer [...] que os procedimentos usados agora pela Igreja não são aqueles usados 
pelos apóstolos, porque com as pregações e com os exemplos de uma vida decente convertiam as pessoas, mas que agora quem não deseja ser católico precisa provar o castigo e a pena, porque usa-se a força e não o amor; que este mundo não poderia continuar assim porque não havia senão ignorância, e nenhuma religião que fosse boa; que a católica lhe agradava bem mais que as outras, mas que esta ainda precisava de grandes regras; e que não estava bem assim, mas que logo o mundo haveria de ver uma reforma geral de si mesmo, porque era impossível que durassem tantas safadezas ${ }^{21}$.

Apesar do propósito acusatório do delator, a denúncia parece plausível quando cotejada com as afirmações que ao longo do tempo Bruno expôs em seus escritos. Para ele, o enobrecimento do homem por meio da ciência, cuja garantia está particularmente no conhecimento dos céus, reside em primeiro lugar no projeto - ou no presságio - de uma libertação universal da humanidade dos estreitos limites estabelecidos pela filosofia e pela teologia escolásticas, pela religião cristã e pelas leis injustas. O livre pensador que gostava de definir-se com os versos de Ariosto "d’ogni legge nemico e d’ogni fede" ["inimigo de toda lei e de todo credo"] considerava que uma teologia racional constituiria a alternativa histórica aos sectarismo das

\footnotetext{
21 "[...] d'avergli sentito dire [...] che il proceder che usa adesso la Chiesa, non è quello che usavano gl'apostoli, perché quelli con le predicationi et con glesempi di buona vita convertivano la gente, ma che hora chi non vuol esser catholico, bisogna che provi il castigo et la pena, perché si usa la forza et non l'amore; che questo mondo non poteva durar cosi perché non v'era se non ignoranza, et niuna religione che fosse buona; che la cattolica gli piaceva ben piu de l'altre, ma che questa ancora havea bisogno di gran regole; et che non stava bene cosi, ma che presto il mondo havrebbe veduto una riforma generale di se stesso, perché era impossibile che durassero tante corruttele" (BRUNO, Procès, 2010, doc. 10, terceira denúncia de Giovanni Mocenigo (Veneza, 29 de maio de 1592), p. 41).
} 
diversas confissões numa época de guerras religiosas e perseguições ferozes. Em Spaccio de la bestia trionfante [Expulsão da besta triunfante] (Londres 1584), ele havia esboçado uma reforma geral das virtudes e dos vícios organizados através de um exercício mnemônico aplicado às constelações celestes. Na base estava a convicção de que o heliocentrismo de Nicolau Copérnico teria aberto o caminho para repensar completamente a filosofia, o homem e Deus, o que traria muitas consequências desde a perspectiva da história da civilização.

Quem poderia ser, pois, tão vil e descortês - é a pergunta retórica de Bruno em La cena de le ceneri $[A$ ceia de Cinzas] (1584) - ante o estudo desse homem [Copérnico] que - deixando de lado tudo aquilo que fez, disposto pelos deuses como uma aurora que deveria preceder a saída deste Sol da antiga e verdadeira filosofia, durante tantos séculos sepultada nas cavernas tenebrosas da ignorância cega, maligna, proterva e invejosa -, considerando aquilo que ele não pôde fazer, quisesse colocá-lo no mesmo saco da gregária multidão que discorre, guia-se e precipita-se mais por ouvir uma fé bruta e ignóbil, em vez de considerá-lo como um entre aqueles que, graças a um feliz engenho, puderam orientar-se e elevar-se com a fidelíssima orientação do olhar da inteligência divina?"22

Antes de Bruno, o matemático inglês Thomas Digges havia ressaltado que a rotação axial da Terra, ao tirar dos céus

22 "Chi dunque sarà sì villano e discortese verso il studio di quest'uomo [Copernico], che, avendo posto in oblio quel tanto che ha fatto, con esser ordinato dagli dei come una aurora, che dovea precedere l'uscita di questo sole de l'antiqua vera filosofia, per tanti secoli sepolta nelle tenebrose caverne de la cieca, maligna, proterva ed invida ignoranza; vogli, notandolo per quel che non ha possuto fare, metterlo nel medesmo numero della gregaria moltitudine [...]" (BRUNO, La cena delle Ceneri, 2000, p. 25) [Aqui citado da edição brasileira: BRUNO, 2012, p. 41-42]. 
a tarefa de produzir o dia e a noite no arco de vinte e quatro horas, abria a possibilidade de ampliar indefinidamente o cosmos. "O motivo principal que levou alguns a considerar que os céus são finitos - observava numa famosa paráfrase em inglês de partes do primeiro livro do De revolutionibus copernicano - é o movimento que eles lhe atribuíram de maneira inquestionável" ${ }^{23}$. Na verdade, um dos argumentos aristotélicos decisivos contra o infinito cosmológico havia sido mesmo a necessidade que o movimento diurno dos céus fosse realizado num tempo finito.

Nos diálogos italianos e nas obras latinas subsequentes, especialmente nos assim chamados poemas de Frankfurt de 1591, Bruno afirma a pluralidade infinita dos mundos pensados em analogia com o sistema solar (GRANADA, 2007, p. 149-156). Essa visão implicava um questionamento radical do lugar do homem no universo, de sua relação com a natureza e, enfim, com Deus. Renunciar a uma perspectiva antropocêntrica não implicava talvez repensar o próprio conceito de Providência?

Essa renúncia àquilo que poderíamos chamar de "princípio antrópico", que coloca o homem como centro e fim da natureza, já havia sido posta em xeque por outros defensores do sistema copernicano e da pluralidade dos mundos. O físico e matemático Giovanni Battista Benedetti, por exemplo, em suas Disputationes mathematicae et physicae (Torino 1585), havia considerado absurdo que todo o cosmos estivesse a serviço dos acontecimentos terrestres. Como se pode ler numa carta sobre o "fim dos corpos celestes" (de fine corporum coelestium) endereçada ao dignatário savoiano Filiberto Pingone:

23 "For the cheefest reason that hath moved some to thincke the Heaven limited was Motion, whiche they thoughte without controversie to bee in deede in it" (DIGGES, 1934, p. 69-117; p. 83-95; p. 91). 
Desejas saber, além da revelação, qual é o fim para o qual foram criados os corpos celestes, servindo-te [tão somente] da razão humana? Então não deves ter como certo que regem um corpo desprezível quanto a Terra cheia de águas, animais e plantas, dado que eles são corpos divinos, inumeráveis e dotados de enorme grandeza e movimentos rapidíssimos. Não considero que estão certos aqueles que seguem o ensinamento de Aristarco de Samos e de Copérnico. Com base em sua teoria não se deveria certamente crer que o universo inteiro não tenha outro fim senão reger este centro do epiciclo lunar ([me refiro à Terra] seguindo seu modo de falar). Seria realmente abominável privar os centros dos outros epiciclos planetários de semelhantes influxos [celestes]. Seria irracional, se aquela teoria, que consideram a mais convincente, fosse verdadeira. Para tal propósito não tem valor algum as objeções de Aristóteles, o qual afirma que os corpos celestes não se geram nem se dissolvem dado que os nossos antigos predecessores nunca observaram alterações nos céus. De fato, um habitante hipotético do céu não poderia certamente observar as mudanças que ocorrem na Terra e em suas proximidades, dado que consideram suas partes e não o todo. Por isso, nada exclui que possa haver mudanças particulares mesmo no céu ${ }^{24}$.

\footnotetext{
24 "Si absque lumine superiori, in quem finem facta fuerint corpora coelestia, scire desideras, et humanam rationem sequi volueris, putandum tibi non erit ea solum effecta esse, ut tam vile corpus, ut est terra aquis irrigata, animalia, et plantas regant, cum ea corpora sint divina, in numero incomprehensibilia, maximis magnitudinibus, et motibus velocissimis, praedita, id etiam minus putabunt hii, qui opinionem Aristarchi Samii, et Nicolai Copernici sequuntur, quorum ratione fieri non potest, ut credant, eius, quod ex vniverso reliquum est, alium finem non habere, quam regimen huius centri epicycli Lunaris, ut illorum more loquar. Quam enim turpe esset si centra aliorum epicyclorum planetarum tali regimine privarentur, id quod nullo modo cum ratione consentit, si tam vera est ea opinio, quemadmodum rationabiliorem eam existimant. Neque quid quam valet opinio Aristotelis, qui corpora coelestia, ab ortu, et interitu libera esse sentit, dicens superioribus saeculis, a nostris antiquis nullam unquam animadversam fuisse alterationem in coelo, cum non videat si quis esset in coelo, neque etiam observare posset alterationes que in Terra, et circa Terram fiunt, quae in partibus, et non in toto spectantur: unde etiam fieri potest, ut in coelo sint particulares alterationes" (BENEDETTI, Diversae speculationes, p. 255).
} 
O programa filosófico de Bruno é ainda mais radical. Se para Benedetti e outros pensadores, dentre os quais o famoso professor neoplatônico Francesco Patrizi, a infinitude do espaço é uma extensão ilimitada para além da abóbada celeste, para Bruno todo o espaço está cheio de vida e povoado por mundos infinitos.

Especialmente sobre o tema da pluralidade dos mundos, Bruno deveria se confrontar muitas vezes com os inquisidores. No sumário do processo, compilado em 1598, a questão da pluralidade dos mundos (plures esse mundos) ocupa um capítulo próprio dentre os principais erros doutrinários de Bruno (Procès, 2000, doc. 51, p. 299-309). Sabe-se pelos documentos que o tema foi abordado em diversos interrogatórios (terceiro, décimo segundo, décimo quarto e décimo sétimo). Em 24 de março de 1597, ele foi explicitamente exortado a abandonar tais vanità [fantasias] cosmológicas: "Então ele foi advertido a abandonar tais fantasias relativas à pluralidade dos mundos" (Deinde fuit adminitus ad relinquendum huiusmodi eius vanitates diversorum mundorum) (BRUNO, Procès, 2000, doc. 49, p. 241).

Por outro lado, Bruno estava convicto de que sua própria concepção era piedosa. A figura de Acteão, o caçador transformado em cervo por Diana e devorado pelos próprios cães de caça, torna-se nos Eroici furori alegoria do intelecto que, por meio da contemplação da natureza, descobre que o infinito umbrátil no mundo externo é o fundamento do próprio ser do qual está afastado (BEIERWALTES, 1978, p. 345-354). Para Bruno, o infinito é pois o elo de ligação entre antropologia, cosmologia e teologia. Ele considerava que tal concepção, embora inovadora, não deveria incorrer na censura teológica, uma vez que exaltava a onipotência de Deus: 
Não é preciso temer a censura dos espíritos honrados, religiosos autênticos e, ainda assim, naturalmente homens de bem, amigos da conversação civil e das boas doutrinas, pois, quando a examinarem bem, verão que essa filosofia não contém somente a verdade, mas também favorece a religião mais que qualquer outro tipo de filosofia, como aquelas que afirmam que o mundo é finito; que o efeito e a obra da potência divina são finitos; [...] e muitos outros absurdos que, não somente por serem falsos, cegam a luz do entendimento, mas também, por serem indolentes e ímpios, apagam o fervor dos bons sentimentos ${ }^{25}$.

\section{Perspectivas cosmológicas no processo inquisitorial de Bruno}

O processo inquisitorial de Bruno nos apresenta uma das sínteses mais emocionantes do seu pensamento e do entrelaçamento de temas metafísico-teológicos, naturais e cosmológicos. Mesmo se as circunstâncias exigissem a cautela do acusado, ele no entanto, como mostra especialmente a primeira fase veneziana do processo, apresenta uma visão de conjunto de sua filosofia numa disputa de vida e morte que o constringe a usar todas as suas energias morais e intelectuais. Tanto Bruno quanto os seus juízes deviam se dar conta do

\footnotetext{
25 "Dalla censura di onorati spiriti, veri religiosi, et anco naturalmente uomini da bene, amici della civile conversazione e buone dottrine, non si de' temere; perché quando bene arran considerato, trovarranno che questa filosofia non solo contiene la verità, ma anco favorisce la religione più che qualsivoglia altra sorte de filosofia: come quelle che poneno il mondo finito; l'effetto e l'efficacia della divina potenza finiti; [...] et altri inconvenienti assai; li quali non solamente come falsi acciecano il lume de l'intelletto, ma ancora, come neghittosi et empii, smorzano il fervore di buoni affetti" (BRUNO, La cena delle Ceneri, 2000, p. 9-158, p. 95-96) [Aqui citado da edição brasileira: BRUNO, 2012, p. 109].
} 
significado abrangente de um processo que ultrapassava a mera disputa entre as partes. Os temas das discussões ecoavam as controvérsias filosófico-científicas do tempo e podia-se imaginar que o êxito iria ter repercussões de longa duração ${ }^{26}$.

O terceiro interrogatório de Bruno, em 2 de junho de 1592, no tribunal de Veneza, é uma verdadeira lição. O acusado, preso faz mais de dez dias, ainda confia em suas capacidades e no possível êxito do processo. Após ter sido interrogado sobre sua própria vida e sobre as peregrinações europeias nos dois primeiros interrogatórios, se lhe pergunta agora sobre seus próprios escritos e ideias. Bruno apresenta uma lista (lamentavelmente perdida) dos títulos, omitindo os mais problemáticos ${ }^{27}$. Expõe o próprio pensamento de modo organizado: parte de considerações metodológicas gerais para passar depois a tratar dos conteúdos que são, por ordem, a cosmologia, a natureza, Deus, a Criação e a Trindade.

A premissa metodológica tem uma importância estratégica fundamental. Adotando uma posição defensiva típica de averroístas e aristotélicos padovanos que cheirava à impiedade - de Pietro Pomponazzi a Cesare Cremonini - Bruno salienta que tem sempre e somente escrito como filósofo e não como teólogo. "Sempre tratei [os temas] de modo filosófico e de acordo com os princípios e a luz natural, não tendo tratado especialmente daquilo que deve ser mantido de acordo com a fé" ${ }^{28}$.

\footnotetext{
${ }^{26}$ A imediata repercussão europeia da condenação de Bruno foi destacada por Ricci (2000, p. 549-557).

${ }_{27}$ O Spaccio, por exemplo, foi 'descoberto' em uma fase muito avançada, quase conclusiva, do processo, presumivelmente em 1599. "Et essendosi [...] havuto notitia che nel Santo Offitio di Vercelli eri stato denunziato, che mentre tu eri in Inghilterra eri tenuto per ateista et che havevi composto un libro di Trionfante bestia [...]" (BRUNO, Procès, doc. 66, p. 481).

${ }^{28}$ (Idem, doc. 13, p. 64): "[...] sempre ho diffinito filosoficamente et secondo li principii et lume naturale, non havendo riguardo principal a quel che secondo la fede deve essere tenuto".
} 
Se em suas obras se encontrar algo de contrário à fé, acrescenta ele, isso depende tão somente da perspectiva. Assim, justifica-se, ele não tem especulado diversamente de Aristóteles ou Platão, "que do mesmo modo indiretamente são contrários à fé, muito mais contrários que os artigos propostos e defendidos de maneira filosófica"29. Definitivamente, diante dos inquisidores, Bruno esconde o projeto de uma emancipação filosófica universal que transparece nos escritos e na denúncia de Mocenigo, atenua as cores e distingue entre o que se pode justificar racionalmente e o que se deve acreditar com base na fé. Após apresentar essa premissa metodológica, ele passa a expor a própria doutrina, "só indiretamente" contrária à fé.

Bruno indica o ponto de partida da sua própria concepção na cosmologia infinitista. E a apresenta como expressão digna da potência infinita da divinidade. A tese copernicana do movimento terrestre, inserida nesse contexto, é apresentada assim: "Afirmei que há infinitos mundos particulares semelhantes à Terra; a qual, com Pitágoras, considero um astro, semelhante à Lua, outros planetas e outras estrelas, que são infinitas" ${ }^{\prime 30}$. Aparece aqui uma característica fusão bruniana do heliocentrismo copernicano, indicado como doutrina pitagórica, e infinitismo, aplicado também ao número dos corpos celestes perdidos no espaço sem limites. De acordo com a delação de um colega de prisão, Matteo de Silvestris, "muitas vezes ensinava que todas as estrelas visíveis eram mundos"31.

${ }^{29}$ (Ibid, p. 65): "[...] che nel medesmo modo indirettamente sono contrarii alla fede, anci molto più contrari che li articuli da me filosoficamente proposti et diffesi". 30 "[...] ho dechiarato infiniti mondi particulari simili a questo della Terra; la quale con Pittagora intendo uno astro, simile alla quale è la Luna, altri pianeti et altre stelle, le qual sono infinite" (BRUNO, Procès, 2000, p. 67).

31 (Idem): "[...] più e più volte insegnava che tutte le stelle che si vedeano erano mondi". 
A natureza, prossegue Bruno no terceiro interrogatório, coincide com a providência na acepção de "sombra e vestígio da divinidade" que transmite a vida ao universo como a alma ao corpo. Numa segunda acepção, "providência" significa a onipresença de Deus no universo de "modo inefável".

Após tratar do cosmos e da natureza, movendo-se do particular ao universal, Bruno fala sobre Deus. Atribui-lhe três atributos, distintos da razão, mas que coincidem entre si: potência/mente, sapiência/intelecto e bondade/amor. O primeiro atributo confere o ser aos entes. O segundo, ou seja, o intelecto, traz aos entes as distinções individuais, e o terceiro, o amor, os harmoniza. Bruno compreende a Criação como dependência ontológica do criado em relação ao Criador. Durante o processo, não chega a afirmar a eternidade do mundo, mas se limita a sustentar que a sua concepção é válida tanto ao se colocar um fim temporal ao mundo, quanto no caso contrário:

Ao sustentar que o mundo era causado e produzido, afirmava que de acordo com tudo o ser é dependente da causa primeira; de modo que não desprezava a criação, que penso também Aristóteles a tenha expresso, chamando a Deus ser, do qual depende o mundo e toda a sua natureza; assim, segundo a explicação de São Tomás, seja na eternidade ou no tempo, de acordo com tudo o seu ser depende da causa primeira e nada é nele independente ${ }^{32}$.

\footnotetext{
32 "Ponendo poi il mondo causato e produtto, intendeva che secondo tutto l'essere è dependente dalla prima causa; di sorte che non abbhorriva dal nome della creatione, la quale intendo che anco Aristotele habbia espressa, dicendo Dio essere, dal quale il mondo e tutta la sua natura depende; si che, secondo l'esplicatione de san Thomaso, o sia eterno o sia in tempo, secondo tutto lo essere suo è dependente dalla prima causa et niente è in esso independentemente" (BRUNO, Procès, 2000, p. 69).
} 
Não obstante a cautela, essa afirmação do terceiro interrogatório será transcrita pelos inquisidores romanos, na última fase do processo, com a indicação: "Circa aeternitatem mundi" ["Sobre a eternidade do mundo"]. Ocorre ainda que, no décimo segundo interrogatório, Bruno é instado pelos juízes a se pronunciar mais uma vez sobre a questão, e ele mantém a mesma posição ${ }^{33}$.

No terceiro interrogatório, Bruno discute demoradamente a Trindade. Do ponto de vista filosófico, a encarnação de Deus não lhe resulta compreensível. Admite ter duvidado disso, do mesmo modo em que confessa não ter considerado "pessoa" Filho e Espírito Santo. Este poderia ser entendido também como anima mundi:

Desse modo, que o Espírito divino seja uma terceira pessoa, não o pude compreender de acordo com o que se deve acreditar; mas de acordo com o modo pitagórico e conforme mostra Salomão, o compreendi como alma do universo, ou então como aquele que assiste ao universo, iuxta illud dictum Sap[ientiae] Salomonis: 'Spiritus Domini replevit orbem terrarum, et hoc quod continet omnia ${ }^{34}$.

Somente sobre o Pai, ou seja, da primeira pessoa da Trindade, Bruno afirma ter acreditado aquilo que se requer de qualquer cristão. Na verdade, mesmo considerando que intelecto e amor compartilham a essência da primeira pessoa,

33 (Idem, p. 313): "In duodecimo constituto in substantia eodem modo respondet et, factis sibi obiectionibus, negat".

${ }^{34}$ (Ibidem, doc. 13, p. 71): "Cosi quanto al Spirito divino per una terza persona, non ho possuto capire secondo il modo che si deve credere; ma secondo il modo pittagorico, conforme a quel modo che mostra Salomone, ho inteso come anima dell'universo, overo assistente all'universo, iuxta illud dictum Sap[ientiae] Salomonis: 'Spiritus Domini replevit orbem terrarum, et hoc quod continet omnia'. 
ainda assim não considera adquado referi-las como "pessoas" distintas.

Dessa síntese do próprio pensamento apresentada aos inquisidores emerge o entrelaçamento de temas astronômicos, cosmológicos, físicos, metafísicos e teológicos, além da tensão entre a verdade da fé e a concepção vitalista e infinitista que Bruno diz sustentar guiado pelo 'lume natural. Ele não tergiversa, mas procura abrir para si um espaço de liberdade filosófica indiretamente contrária à fé.

Por fim, há a problemática copernicana. No sumário do processo, uma subdivisão é dedicada exatamente à questão "circa motum Terrae" ["sobre o movimento da Terra"] (BRUNO, Procès, 2000, doc. 51, p. 389). Bruno havia defendido a doutrina copernicana diante de seus juízes chegando até a oferecer uma interpretação vitalista:

Que seja animal racional - havia explicado - vem explicitado pela sua ação racional e intelectual, que se encontra nas leis do seu movimento em torno ao próprio centro, no outro em torno do Sol e no outro em torno aos eixos dos seus pólos; essa lei não pode existir sem o intelecto muito mais interior e próprio que exterior e alheio, porque se o próprio sentido encontra-se nas formigas, abelhas e serpentes, e no homem, ainda mais propriamente deve encontrar-se na Mãe, e não se lhe atribui um [ato] exterior de atração, impulso, rotação, constante e permanente ${ }^{35}$.

35 "Che sia animale rationale - aveva spiegato-è manifesto dall'atto suo rationale intellettuale, che si vede nelle regole del suo moto circa il proprio centro, l'altro circa il Sole e l'altro circa l'asse delli suoi poli; la qual regola non può essere senza l'intelletto più degnamente interiore e proprio che esteriore e alieno, perché, se proprio senso si trova nelle formiche, api et serpenti, e nell'huomo, molto più degnamente deve trovarsi nella Madre, e non attribuili un esteriore trudente, spingente, rotante, saepe idem inculcando" (BRUNO, Procès, doc. 51, p. 391). 
Contra a doutrina astronômica do movimento da Terra e da imutabilidade do firmamento, foram-lhe contrapostos os versículos bíblicos do Eclesiastes (1:4-6): "generatio praeterit et generatio advenit terra vero in aeternum stat oritur sol et occidit et ad locum suum revertitur ibique renascens gyrat per meridiem et flectitur ad aquilonem". Diante da pergunta “Terra non autem stat in aeternum (A Terra não 'está' portanto [parada] no eterno)?", o imputado retruca que os versículos não se referem ao movimento local, mas sim ao "estado" de todos os seres, ou seja, à geração e à corrupção. Quanto ao nascer e ao pôr do Sol (Sol oritur et occidit), acrescenta que a expressão deveria se referir não ao movimento real do astro, mas tão somente à aparência produzida pelo movimento terrestre. Por fim, lhe foi reprovado de se afastar da exegese dos Padres da Igreja, ao que ele, pelo que foi relatado, respondeu assim:

À objeção de que a sua posição contradiz a autoridade dos Santos Padres, ele respondeu que "não enquanto santos, bons e exemplares, mas enquanto são menos práticos que os filósofos e menos atentos às coisas da natureza"36.

\section{Contextualização e perspectivas de investigação}

Alguns anos depois, a acusação de defender o movimento terrestre contra a autoridade da Sagrada Escritura e

\footnotetext{
${ }^{36}$ Idem, p. 389 "Et ad obiectionem, quod repugnat haec sua positio auctoritati sanctorum Patrum, respondet, che 'non in quanto sono santi, buoni et essemplari, ma in quanto che sono meno de' filosofi prattichi e meno attenti alle cose della natura”.
} 
dos Padres seria renovada por um dos inquisidores de Bruno, Roberto Bellarmino, contra o carmelita calabrês Antonio Foscarini, autor de uma Lettera sopra l'opinione de' Pitagorici e del Copernico [Carta sobre a opinião dos Pitagóricos e de Copérnico] (Nápoles 1615), que volta a sustentar a compatibilidade entre o heliocentrismo e a Bíblia. Numa carta áspera dirigida a ele e a Galileu (12 de abril de 1615), Bellarmino lembrava que o Concílio de Trento havia proibido de apresentar as Escrituras contra o "senso comum dos Santos Padres". Ele havia recebido uma carta sincera de Foscarini, cravejada de referências patrísticas, mas isso não lhe parecia suficiente. $\mathrm{Na}$ verdade, Bellarmino acrescentava com uma certa satisfação:

Se Vossa Paternidade quiser ler não digo somente os Santos Padres, mas os comentários modernos sobre o Gênesis, sobra os Salmos, sobre o Eclesiastes, sobre Josué, encontrará que todos estão de acordo em apresentar ad literam que o Sol está no céu e gira [...].

O erro de Foscarini foi o de não ter levado em conta, além dos Padres, a interpretação dos teólogos modernos.

Considerai agora prudentemente se a Igreja pode aceitar que se atribua às Escrituras um sentido contrário a todos os Santos Padres e a todos os comentadores gregos e latinos. Nem se pode responder que esta é uma questão de fé, pois se não é questão de fé ex parte obiecti, é questão de fé ex parte dicentis, e assim seria herético quem afirmasse que Abraão não teve dois filhos e Jacó doze, bem como quem afirmasse que Cristo não nasceu de Virgem, porque isso o diz o Espírito Santo pela boca de Profetas e Apóstolos. ${ }^{37}$

${ }^{37}$ Bellarmino a Foscarini (12 de abril de 1615), p. 215-216: "Consideri hora lei con la sua prudenza se la Chiesa può sopportare che si dia alle Scritture un 
Um fio tênue liga o processo bruniano à subsequente censura de Copérnico e às ações intimidatórias empreendidas nas disputas de Foscarini e Galilei. Em 1615, quando Galilei ainda pensava em poder ter ao seu lado na defesa da causa copernicana figuras de alta posição como o cardeal Bellarmino, foi advertido pelo nobre defensor das ciências, seu amigo $\mathrm{Fe}$ derico Cesi, que lhe escreveu em 12 de janeiro de 1615:

Quanto à opinião de Copérnico, o próprio Bellarmino, um dos chefes na congregação que trata dessas coisas, me disse que a considera herética, e que o movimento da Terra, sem dúvida alguma, é contrário à Sagrada Escritura ${ }^{38}$.

Bellarmino não é o único Inquisidor do processo bruniano a se envolver nas subsequentes ações de repressão e censura nas disputas entre os mais eminentes pensadores e cientistas em relação às suas teorias cosmológicas. Um dos consultores responsáveis, em 1596, pela leitura dos escritos de Bruno com o objetivo de extrair deles as teses heréticas, Pedro Juan Saragoza (BRUNO, Procès, doc. 45, p. 225), foi um dos censores mais intransigentes da Nova de universis philosophia, de Patrizi. Num documento de 8 de outubro de 1592, assinado por Saragoza junto com o mestre do Sacro Palazzo Bartolomeo de Miranda (que também esteve presente em algumas sessões do processo de Bruno), foram apresentadas algumas teses

senso contrario a tutti li santi Padri et a tutti li espositori greci e latini. Né si può rispondere che questa non sia materia di fede, perché se non è materia di fede ex parte obiecti, è materia di fede ex parte dicentis, et cosi sarebbe heretico chi dicesse che Abramo non abbia havuto due figlioli et Iacob dodici, come chi dicesse che Christo non è nato di Vergine, perché l'uno e l'altro lo dice lo Spirito Santo per bocca de Propheti et Apostoli".

${ }^{38}$ Federico Cesi a Galileu (Acquasparta, 12 de janeiro de 1615). Ver: Galileo (1968, vol. 12, p. 128-131; p. 129). 
próximas àquelas de Bruno, dentre as quais o vitalismo planetário, a infinitude espacial e algumas passagens cosmológicas que sugeriam uma adesão à teoria copernicana (Patrizi, na verdade, havia se limitato a sustentar a rotação axial da Terra):

[...] Diz que a rotação da Terra é mais razoável que aquela do céu ou dos astros superiores. E vincula à teoria de Nicolau Copérnico afirmando que o céu estrelado está parado, inclusive as estrelas, enquanto a Terra se move.

Tal doutrina apresenta um duplo erro, ou seja que a Terra gira, tese contrária às Sagradas Escrituras, e em segundo lugar que os céus, em particular os astros superiores, não se movem. Não vou considerar as razões aduzidas por Aristóteles no segundo livro do De coelo [...] para demonstrar a imobilidade da Terra, mas o Salmo 92 recita: "Firmavit Deus orbem" [Deus fixou a esfera terrestre, e mundo não se moverá. [...] O início do Eclesiastes diz que a Terra está [parada] por toda eternidade.

Quanto ao movimento dos céus, ele pode ser demonstrado mencionando os teólogos, os quais sustentam que o céu vai parar no dia do Juízo [...]. Quanto ao Sol, o Eclesiastes afirma explicitamente que o Sol se move, nasce e desce, e retorna ao ponto de partida, donde renascendo volta para o ocidente mantendo-se ao sul. [Patrizi] afirma que os astros são viventes e até mesmo providos de intelecto [...]. Sustentar que os astros e os corpos celestes são viventes e guiados pelo intelecto é tese contrária ao consenso dos Padres da Igreja.

Sustenta também que fora do cosmos há um espaço infinito que transmite a luz [lumen] às estrelas e planetas e que tal luz [lumen] estende-se ao infinito [...]. Chama a isso de 'Céu Empíreo'.

Esses são alguns sonhos tenebrosíssimos que se afastam do caminho seguro para acabar em precipícios. Na verdade, Deus Ótimo Máximo criou tudo segundo peso, número e medida. Por isso, todos aceitam que um corpo infinito em ato e uma pluralidade infinita de 
entes em ato são impossíveis. A propósito do céu empíreo sejam consultados os Padres da Igreja e São Tomás ${ }^{39}$.

Um outro censor de Patrizi, Benedetto Giustiniani, figura entre os onze teólogos que, em fevereiro de 1616, condenaram o sistema copernicano (BALDINI; SPRUIT, 2009, p. 2.216-2.219; p. 1.477).

$\mathrm{Na}$ Itália dos tempos da Inquisição, o medo do inimigo externo, a Reforma, que fora extirpada pela raiz da Península, volta-se contra o inimigo interno ${ }^{40}$. Assim era compreendido tudo o que podia colocar em perigo a ordem estabelecida e as autoridades constituídas, também no campo cultural. $\mathrm{O}$ dissenso e o espírito crítico não foram confrontados com a

\footnotetext{
39 "[...] ait quod Terram revolvi longe videtur esse rationi consonantius, quam Coelum, vel suprema astra moveri. Et refert sententiam Nicolai Copernici dicentis Coelum sydereum stare simul cum stellis, Terram vero moveri.

In hac doctrina duo sunt falsa, et contra sacras literas videlicet Terram revolvi. S[ecundum] Coelos praesertim suprema astra non moveri. Omitto quae adducit Arist. s[ecundo] De Coelo [...] ad probandam stabilitatem Terrae sed in Ps. 92 "Firmavit Deus orbem" Terrae, qui non commovebitur. [...] In initio Ecclesiaste Terra autem in aeternum stat.

Quod autem Coeli moveantur, probari potest p[rimo] nam est sententia Theologorum, quod coelorum motus cessabit in die Iudicii [...]. De Sole aperte habetur in Ecclesiaste quod movetur, oritur Sol, et occidet, et ad locum suum revertitur, ibique renascens gyrat per meridiem, et flectitur ad Aquilonem.

[...] Ait quod Astra vivunt, immo quod habent Intellectum [...]

Dicere quod Astra et sydera vivant, et intellectu polleant est contra sententiam communem receptam apud Patres [...].

Dicit extra Mundum esse spatium quoddam infinitum quod impletur Lumine stellarum, et planetarum, et tale lumen extendi in infinitum [...] et hoc vocat Coelum empyreum. [...]

Hoc est somniare per altissimas tenebras, et a via communi declinando in praecipitia ruere, nam cum Deus opt. Max. omnia in pondere, numero, et mensura produxerit, nullum infinitum corpus actu dari nullamque rerum subsistentium multitudinem actu infinitam omnes viri fatentur. De Coelo empyreo consultat Patres, et sanctum Thomam" (BALDINI; SPRUIT, 2009, p. 2.216-2.219).

${ }^{40}$ Um olhar de relance sobre os estudos da censura do Índice é apresentado por Black (2013, cap. 7, "La censura").
} 
força dos argumentos, mas com a violência. Há ainda muito que se investigar para reconstruir em detalhes as dinâmicas inquisitoriais e as suas relações com o desenvolvimento científico na Itália entre os anos setenta do século XVI e a metade do século seguinte. Dentro desse cinquentenário trágico, os expoentes mais importantes da cultura científica renascentista passaram pelo crivo das autoridades eclesiásticas, foram frequentemente perseguidos e submetidos a censuras humilhantes e condenações. Passou-se, na verdade, dos primeiros atos inquisitoriais dirigidos contra intelectuais da estatura de Girolamo Cardano e Giovanni Battista della Porta, particularmente pelas suas propensões mágicas e astrológicas, à impressionante abjuração de Galilei ${ }^{41}$. O auto-de-fé de Bruno em 1600 apresenta-se como o ponto central desse período. Os anos do seu processo são os mesmos da elaboração do índice clementino, que interditou ou proibiu várias obras filosóficas e científicas, dentre as quais as de Patrizi e Telesio. São também anos decisivos nos quais se define a diferença entre a exegese bíblica e a teoria copernicana. O Santo Ofício e a Congregação do Índice não pretendiam deixar nenhum espaço para as novas visões do cosmo e da natureza ou para o ecletismo - que é uma das características mais importantes da estação cultural que estava por se fechar. A perda da centralidade da Terra, com Copérnico, e o consequente deslocamento do homem iriam atingir a confiança nos dogmas centrais da fé cristã, começando pela Providência Divina como havia sido concebida até então. A questão ética da astronomia na época pós-copernicana emerge não somente do encontro e do desencontro com os

\footnotetext{
${ }^{41}$ Para uma visão panorâmica sobre a "lotta contro la nuova filosofia" [luta contra a nova filosofia] pode-se consultar Del Col (2006, p. 552-565).
} 
lugares comuns da cultura astronômica clássica e renascentista, mas também e sobretudo com a teologia em sua cristalização pós-tridentina.

\section{Referências}

BALDINI, H; SPRUIT, L. (Ed.). Catholic Church and Modern Science: Documents from the Archives of the Roman Congregation of the Holy Office and the Index. Vol. 1, SixteenthCentury Documents, Tome 2. Roma: Libreria Editrice Vaticana, 2009.

BEIERWALTS, Werner. "Actaeon: Zu einem mythologischen Symbol Giordano Brunos." Zeitschrift für philosophische Forschung 32, p. 345-354, 1978.

BILINSKI, Bronisław. Il pitagorismo di Niccolò Copernico. Wrocław: Zakł. Narod. In: Ossolińskich Wydawn. Polskiej Akad. Nauk, 1977.

BLACK, Christopher F. Storia dell'inquisizione in Italia: Tribunali, eretici, censura. Roma: Carocci, 2013.

BRUNO, Giordano. Oeuvres complètes. Vol. 1. Le procès. Paris: Les Belles Lettres, 2000.

. La cena delle Ceneri. In: Dialoghi filosofici italiani, a cura di Michele Ciliberto. Milano: Mondadori, 2000. [Aqui citado da edição brasileira: BRUNO, Giordano. A ceia de Cinzas. Trad. Luiz Carlos Bombassaro, Caxias do Sul, 2012, p. 41-42]. 
BRAHE, T. De disciplinis mathematicis. In: Opera omnia. A cura di John Louis Emil Dreyer. Copenhagen: 1913-1929; reprinted Amsterdam: Swets \& Zeitlinger, 1972. Vol. 1.

CHRISTIANSON, John Robert. On Tycho's island: Tycho Brahe and His Assistants, 1570-1601. Cambridge: Cambridge University Press, 2000.

CANONE, Eugenio. "La fine di tutte le cose? Lo Spaccio e l'Apocalisse, In: Magia dei contrari: cinque studi su Giordano Bruno. Roma: Edizioni dell'Ateneo, 2005.

CASSIRER, E. Individuum und Kosmos in der Philosophie der Renaissance. Leipzig: Teubner, 1927.

CICERONE. De natura deorum (Sobre a natureza dos deuses), vol. II. Cambridge, Univ. Press, 1880-1885.

CONNER, Clifford D. A People's History of Science: Miners, Midwives, and "Low Mechanicks". New York: Nation Book, 2005.

DEL COL, Andrea. L'Inquisizione in Italia dal XII al XXI secolo. Milano: Mondadori, 2006.

DIGGES, Thomas. A Perfit Description of the Caelestial Orbes according to the most aunciente doctrine of the Pythagoreans, latelye revived by Copernicus and by Geometricall Demonstrations approved In: RARICK, F; LARKEY, J. “Thomas Digges, the Copernican System and the Idea of Infinity of the Universe in 1576." Huntington Library Bulletin 5, p. 69-117 (p. 83-95), p. 91, 1934. 
FIRPO, Luigi. Il processo di Giordano Bruno. Roma: Salerno Editrice, 1993.

GALILEU, Galilei. Le opere. Firenze: Barbera, 1968. Vol. 12.

GARIN, Eugenio. Lozodiaco della vita: la polemica sull'astrologia dal Trecento al Cinquecento. Roma: Laterza, 2007.

GRANADA, Miguel Ángel. "Introduction" a Giordano Bruno, Des Fureurs Héroiques. Paris: Les Belles Lettres, 1999.

- El debate cosmológico en 1588: Bruno, Brahe, Rothmann, Ursus, Röslin. Napoli: Bibliopolis, 1996.

. "Synodi ex mundis." In: Bruniana \& Campanelliana 13, p. 149-156, 2007.

JARDINE, Nicholas; SEGONDS, Jardine. La guerre des astronomes: La querelle au sujet de l'origine du système géohéliocentrique à la fin du XVIe siècle. Parigi: Les Belles Lettres, 2008.

KUSUKAWA, Sachiko. The Transformation of Natural Philosophy: The Case of Philip Melanchthon. Cambridge: Cambridge University Press, 1995.

OMODEU, Pietro. Copernicus in the Cultural Debates of the Renaissance: Reception, Legacy, Transformation. Leiden: Brill, 2014.

ORDINE, Nuccio. La soglia dell'ombra: letteratura, filosofia e pittura in Giordano Bruno. Venezia: Marsilio, 2004. [Traduzido no Brasil como: O umbral da sombra. Literatura, filosofia e pintura em Giordano Bruno. São Paulo: Perspectiva, 2006]. 
PACE, Anna de. Le matematiche e il mondo: Ricerche su un dibattito in Italia nella seconda metà del Cinquecento. Milano: Franco Angeli, 1993.

PICO DELLA MIRANDOLA, Giovanni. De hominis dignitate, In: Opera omnia, vol. 1. [Aqui citado da edição portuguêsa: PICO DELLA MIRANDOLA. Discurso sobre a dignidade do homem. Trad. de Maria de Lurdes Sigardo Ganho. Lisboa: Edições 70, 1989].

PLATONE. Timeo 47 B-C. [Aqui citado da edição brasileira: PLATÃO. Timeu. São Paulo: Hemus, 1981, p. 110].

PORFIRIO. Vita di Plotino, a cura di Giuseppe Girgenti, In: Plotino, Enneadi. Milano: Mondadori, 2002.

RENAISSANCE: "The Rhetoric and Epistemology of Astronomy." In: VALLERIANI, Matteo Valleriani (Ed.). Practical Knowledge. Boston: Springer, 2015.

RICCI, Saverio. Giordano Bruno nell'Europa del Cinquecento. Roma: Salerno Editrice, 2000.

ROSEN, Edward. Three Imperial Mathematicians: Kepler Trapped between Tycho Brahe and Ursus. New York: Abaris Books, 1986.

WESTMAN, Robert. The Copernican Question: Prognostication, Skepticism, and Celestial Order. Berkeley-Los Angeles-London: University of California Press, 2011. 